\title{
A SYBR Green 1-based in vitro test of susceptibility of Ghanaian Plasmodium falciparum clinical isolates to a panel of anti-malarial drugs
}

Neils B Quashie 1,2*, Nancy O Duah², Benjamin Abuaku², Lydia Quaye², Ruth Ayanful-Torgby², George A Akwoviah², Margaret Kweku ${ }^{4}$, Jacob D Johnson ${ }^{5}$, Naomi W Lucchi', Venkatachalam Udhayakumar ${ }^{6}$, Christopher Duplessis ${ }^{3}$, Karl C Kronmann ${ }^{3}$ and Kwadwo A Koram ${ }^{2}$

\begin{abstract}
Background: Based on report of declining efficacy of chloroquine, Ghana shifted to the use of artemisinin-based combination therapy (ACT) in 2005 as the first-line anti-malarial drug. Since then, there has not been any major evaluation of the efficacy of anti-malarial drugs in Ghana in vitro. The sensitivity of Ghanaian Plasmodium falciparum isolates to anti-malarial drugs was, therefore, assessed and the data compared with that obtained prior to the change in the malaria treatment policy.
\end{abstract}

Methods: A SYBR Green 1 fluorescent-based in vitro drug sensitivity assay was used to assess the susceptibility of clinical isolates of $P$. falciparum to a panel of 12 anti-malarial drugs in three distinct eco-epidemiological zones in Ghana. The isolates were obtained from children visiting health facilities in sentinel sites located in Hohoe, Navrongo and Cape Coast municipalities. The concentration of anti-malarial drug inhibiting parasite growth by $50 \%\left(\mathrm{IC}_{50}\right)$ for each drug was estimated using the online program, ICEstimator.

Results: Pooled results from all the sentinel sites indicated geometric mean $I C_{50}$ values of $1.60,3.80,4.00$, $4.56,5.20,6.11,10.12,28.32,31.56,93.60,107.20$, and $8952.50 \mathrm{nM}$ for atovaquone, artesunate, dihydroartemisin, artemether, lumefantrine, amodiaquine, mefloquine, piperaquine, chloroquine, tafenoquine, quinine, and doxycycline, respectively. With reference to the literature threshold value indicative of resistance, the parasites showed resistance to all the test drugs except the artemisinin derivatives, atovaquone and to a lesser extent, lumefantrine. There was nearly a two-fold decrease in the $\mathrm{I}_{50}$ value determined for chloroquine in this study compared to that determined in $2004(57.56 \mathrm{nM})$. This observation is important, since it suggests a significant improvement in the efficacy of chloroquine, probably as a direct consequence of reduced drug pressure after cessation of its use. Compared to that measured prior to the change in treatment policy, significant elevation of artesunate $I C_{50}$ value was observed. The results also suggest the existence of possible cross-resistance among some of the test drugs.

Conclusion: Ghanaian P. falciparum isolates, to some extent, have become susceptible to chloroquine in vitro, however the increasing trend in artesunate $I_{50}$ value observed should be of concern. Continuous monitoring of ACT in Ghana is recommended.

Keywords: Isolates, in vitro, Susceptibility, Inhibition, Plasmodium falciparum

\footnotetext{
* Correspondence: nquashie@noguchi.ug.edu.gh

${ }^{1}$ Centre for Tropical Clinical Pharmacology and Therapeutics, University of

Ghana Medical School, Accra, Ghana

2Epidemiology Department, Noguchi Memorial Institute for Medical

Research, University of Ghana, Accra, Ghana

Full list of author information is available at the end of the article
}

\section{Biomed Central}

(c) 2013 Quashie et al.; licensee BioMed Central Ltd. This is an Open Access article distributed under the terms of the Creative Commons Attribution License (http://creativecommons.org/licenses/by/2.0), which permits unrestricted use, distribution, and reproduction in any medium, provided the original work is properly cited. The Creative Commons Public Domain Dedication waiver (http://creativecommons.org/publicdomain/zero/1.0/) applies to the data made available in this article, unless otherwise stated. 


\section{Background}

Malaria, caused by an infection with Plasmodium falciparum, is complex and affects a significant number of people living in disease-endemic areas of the world, especially sub-Saharan Africa. According to the World Health Organization (WHO) World Malaria Report, there were about 219 million cases of malaria in 2010 and an estimated 660,000 deaths [1]. Most of these cases occur among children within whom the disease can sometimes present in a severe form, often with devastating consequences. Countries in sub-Saharan Africa, comprising some of the poorly developed nations in the world, bear a major part of the disease burden with at least $90 \%$ of the reported deaths $[1,2]$.

In Ghana, malaria is hyper-endemic and remains the most widely diagnosed infectious disease in the country. It is the single most important cause of mortality and morbidity especially among children under five years and pregnant women [3]. The disease is responsible for up to $40 \%$ of daily outpatient consultations at hospitals and clinics across the country, accounting for over $23 \%$ of deaths among children below the age of five years [4-6]. Early presumptive treatment of febrile illness with chloroquine was the mainstay of malaria control in Ghana until 2005 when there was strong indication of P. falciparum resistance to this drug. Reports from drug efficacy study conducted in the country provided strong evidence of the existence of $P$. falciparum isolates that were resistant to chloroquine [7]. Based on this evidence and upon the recommendation of the WHO among others, in 2005 Ghana officially changed from the use of chloroquine to artemisinin-based combination therapy (ACT) as the first choice of antimalarial drugs for the treatment of uncomplicated malaria. At the moment, ACT recommended by the national malaria control programme (NMCP) of Ghana is artesunate-amodiaquine (AA), with artemetherlumefantrine $(\mathrm{AL})$ and dihydoartemisinin-piperaquine (DHAP) as alternatives. It must be emphasized that in the absence of either an effective vaccine or good alternative anti-malarial drugs to ACT, the emergence and spread of artemisinin-resistant parasites would be devastating. Although no resistance to combination therapy has yet been reported in Ghana, it is important that these drugs are closely monitored for early detection of reduced parasite susceptibility, especially as reports have appeared of $P$. falciparum isolates with decreased response to artemisinin in other parts of the world [8].

In vitro test of $P$. falciparum susceptibility to antimalarial drugs is one of the important tools that can be used to monitor the efficacy of anti-malarial drugs, as results of parasite responses to drugs may show early trends in changes to susceptibility to the tested drugs and may serve as an early warning system of resistance development in the parasite population [9]. Although in vivo drug efficacy studies remain the 'gold standard' for assessment of anti-malarial drug resistance, its use is limited because it is prohibitively expensive [10]. Molecular marker determination can also be used to identify the single-nucleotide polymorphisms commonly associated with drug resistance in malaria parasites; however, the methods require specialized equipment, which are costly and the assay is difficult to conduct in the field in real time [11]. Additionally, these markers are not well described for the artemisinins. With the low cost involved in carrying out the assay and the rapidity with which it could be conducted, the in vitro drug sensitivity test has become a strong choice for assessing anti-malarial drug efficacy in disease-endemic areas. The test is not affected by host-confounding factors such as immunity, compliance, concomitant infections, re-infection/recrudescence, poor drug absorption, etc. $[12,13]$. The recently described SYBR Green 1 in vitro assay for assessment makes performing the assay easier and precise [14].

Since Ghana officially changed its malaria treatment policy in 2005, there has been no major nationwide in vitro assessment of parasites responses to anti-malarial drugs. In order to determine if the change in policy has significantly affected the susceptibility of the parasites to anti-malarial drugs, this study was carried out to measure the responses of clinical isolates of $P$. falciparum to antimalarial drugs and compare the outcome with baseline data generated from a similar survey conducted in 2004 [15]. The in vitro susceptibility of P. falciparum isolates to a panel of anti-malarial drugs was assessed using the newly developed SYBR Green 1-fluorescentbased method. The panel of 12 anti-malarials includes the nationally recommended anti-malarial drugs for treatment of uncomplicated malaria in Ghana, drugs used for malaria prevention in travellers, and the previous first-line drug in the country, chloroquine. Crossresistance between drugs from the same chemical class or between drugs with similar modes of action, and correlations between susceptibility to different drug classes were also determined and discussed.

\section{Methods}

\section{Study sites}

Three sentinel sites, Cape Coast, Hohoe and Navrongo, representing three distinct eco-epidemiological zones in Ghana were selected for the study (Figure 1). Cape Coast $\left(5^{\circ} .07^{\prime} \mathrm{N}, 1^{\circ} .11^{\prime} \mathrm{W}\right)$ is the capital of the Central region of Ghana. It has a coastline of about $13 \mathrm{~km}$ and is about $150 \mathrm{~km}$ west of Accra (the capital city of Ghana). Vegetation in this area is mainly coastal savannah. Generally, there are two rainy seasons in this region with the peak 


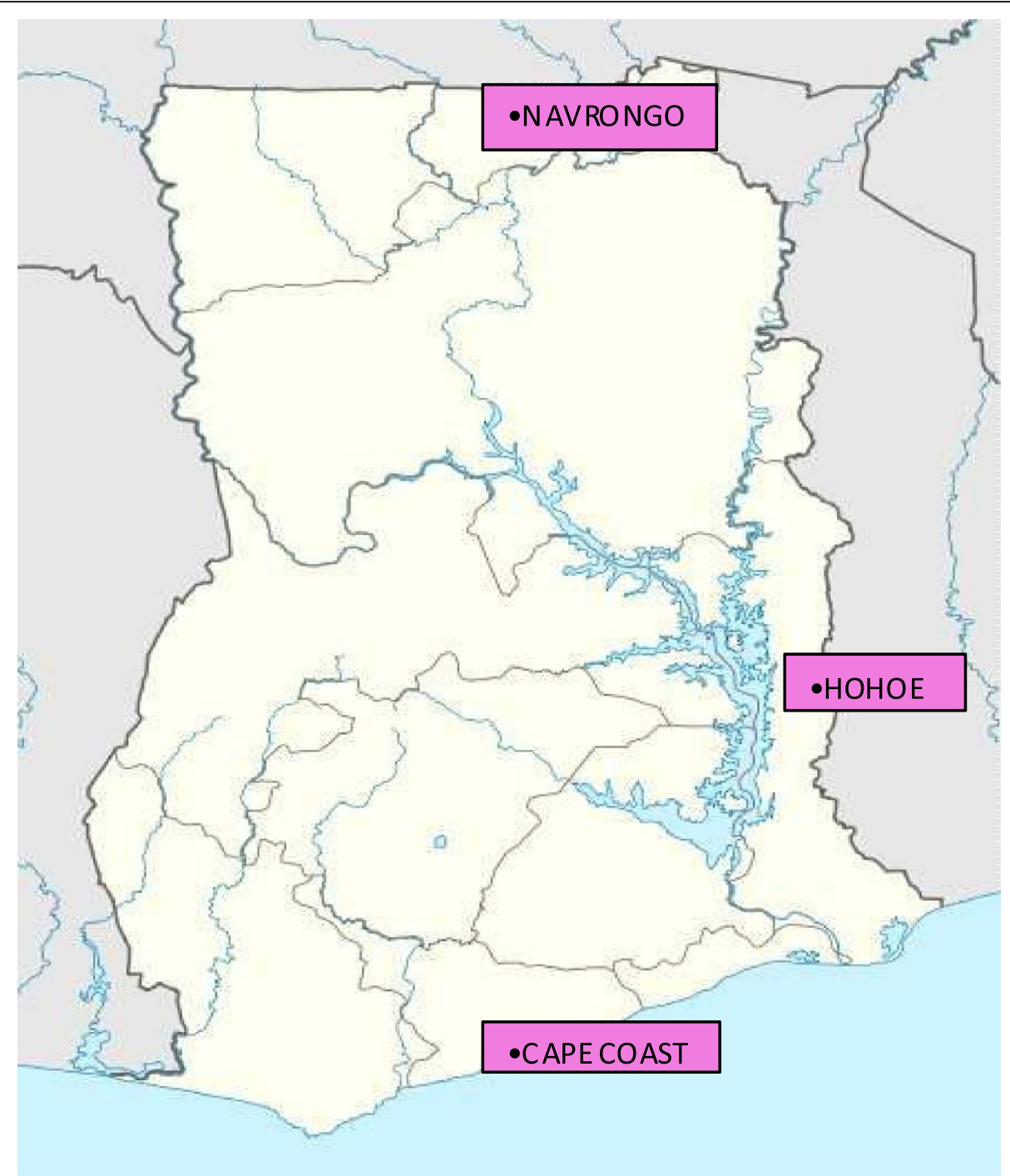

Figure 1 Map of Ghana. A map of Ghana showing the sentinel sites used for the study. The sites are located in three unique ecological zones in Ghana namely Coastal savannah (Cape Coast), Forest (Hohoe) and Guinea savannah (Navrongo). All sites are high transmission areas, but differ from each other in the seasonal variation in malaria rates.

of the major season occurring in June. Numerous rivers and streams in this area end up in a lagoon, creating a vast wetland. The presence of these water bodies allows vector breeding throughout the year, hence malaria transmission in this area is perennial. Hohoe $\left(7^{\circ} 99 \mathrm{~N}\right.$, $\left.0^{\circ} 289 \mathrm{E}\right)$ is the capital of Hohoe municipality and lies in the middle belt of the country, about $220 \mathrm{~km}$ north east of Accra. This area with a vegetation of semi-deciduous forest has two rainy seasons a year, the major one occurring in May-June. Malaria transmission in this site is perennial with a moderate seasonal peak occurring after the major rains in June. Navrongo $\left(10^{\circ} 549 \mathrm{~N}, 1^{\circ} 69 \mathrm{~W}\right)$, is the capital of Kassena-Nankana district. It is about $865 \mathrm{~km}$ north of Accra and lies in the Guinea savannah area in the Upper East region of Ghana. It receives all of its annual rainfall between May and October. The presence of a large reservoir in the district, created to irrigate the land for farming, allows mosquitoes to breed throughout the year. As a result, malaria is perennial but with marked seasonal peak transmission occurring between June and November each year.

\section{Study population and recruitment}

During the main malaria seasons in 2012, children aged six months to nine years presenting to clinics at the study sites with fever or history of fever within the previous 24 hours were screened for inclusion in the investigation. To be included in the study the child had to have documented $P$. falciparum mono-infection at a count ranging between 1,000 and 250,000 per $\mu$ l. Detailed 
information on the study was made available to the parents or guardians of potential participants and they were encouraged to ask questions about any aspect of the study that was unclear to them. A child was only enrolled if the parents or guardians gave their informed consent. Sixty-three (63) patients were recruited from each of the three sites to participate in the study. Permission to carry out this work and ethical clearance were obtained from the Institutional Review Board (IRB) of the Noguchi Memorial Institute for Medical Research (NMIMR), Ghana. This study also received ethical approval from the US Naval Medical Research Unit No. 3 (NAMRU-3) IRB, Cairo, Egypt.

\section{Sample collection}

Prior to treatment, $2 \mathrm{ml}$ of blood were aseptically collected from each participant into a tube containing citrate phosphate dextrose-adenine (CPD-Adenine) and transported to the laboratory for the in vitro drug test within 24 hours. The blood was diluted $20 \times$ with complete RPMI 1640 (Gibco, UK) and used for the assay.

\section{In vitro test of susceptibility of Plasmodium falciparum to anti-malarial drugs \\ Preparation of media, drugs dilutions and test plates}

Incomplete RPMI 1640 culture media supplemented with hypoxanthine and glucose were prepared as previously described [14]. Complete RPMI 1640 contains $\mathrm{NaHCO}_{3}$ and Albumax (Invitrogen). All drugs used in this study were supplied by the World Wide Antimalarial Resistance Network (WWARN), Centers for Disease Control and Prevention (CDC), USA and Walter Reed Army Institute of Research (WRAIR), Kisumu, Kenya. The panel of 12 drugs tested in this study included: amodiaquine, artesunate, artemether, atovaquone, chloroquine, dihydroartemisinin, doxycycline, lumefantrine, mefloquine, piperaquine, quinine, and tafenoquine. Five $\mathrm{ml}$ of stock solutions at $1 \mathrm{mg} / \mathrm{ml}$ were prepared for each anti-malarial drug. Amodiaquine, quinine, mefloquine, and artemisinin were dissolved in $70 \%$ ethanol and lumefantrine and doxycycline in 100\% dimethyl sulphoxide (DMSO). Chloroquine was first dissolved in $1.5 \mathrm{ml}$ deionized water after which the solution was made up to $5 \mathrm{ml}$ with absolute ethanol. The drug solutions prepared were used immediately or stored at $-80^{\circ} \mathrm{C}$ for not longer than one month before use. Stock solutions were further diluted in complete RPMI 1640 to the desired starting concentrations after which two-fold serial dilution was performed in 96-well tissue culture plate to generate ten concentrations for the in vitro drug test. The concentration range for the drugs $(\mathrm{ng} / \mathrm{ml})$ and molecular weights $(\mathrm{g} / \mathrm{mol})$, which was later used to convert to $\mathrm{nM}$ of the test drug concentration were, respectively: amodiaquine $(0.78-200 \mathrm{ng} / \mathrm{ml}, 464.51)$, artesunate (0.78-200 ng/ml, 384.4), artemether $(0.78-200 \mathrm{ng} / \mathrm{ml}$,
$298.37)$, atovaquone $(0.195-50 \mathrm{ng} / \mathrm{ml}, 366.84)$, chloroquine $(7.8-2,000 \mathrm{ng} / \mathrm{ml}, 515.86)$, dihydroartemisinin (0.78-200 ng/ml, 284.35), doxycycline (390.6-100,000 ng/ml, $512.94)$, lumefantrine $(0.78-200 \mathrm{ng} / \mathrm{ml}, 528.94)$, mefloquine (1.9-500 ng/ml, 414.77), piperaquine $(15.6-4,000 \mathrm{ng} / \mathrm{ml}$, 999.55), quinine (15.6-4,000 $\mathrm{ng} / \mathrm{ml}, 321.41)$ and tafenoquine (19.5-5,000 ng/ml, 463.49). Once pre-dosed with the antimalarial drugs, the plates were kept at $4^{\circ} \mathrm{C}$ until use. Test plates were used within three days after preparation.

\section{Drug sensitivity testing}

Two $\mathrm{ml}$ of blood collected from the patients was diluted 20x with complete RPMI 1640 and $100 \mu \mathrm{l}$ was added to each well of the pre-dosed test plate, starting with the lowest concentration of drug and then progressively to higher ones. Wells containing no drug but the diluted patient's blood was included on each plate. The plate was placed in a modular incubator chamber and gassed (gas contains $92.5 \% \mathrm{~N}_{2}, 5.5 \% \mathrm{CO}_{2}, 2 \% \mathrm{O}_{2}$ ). The chamber was placed in an incubator set at $37^{\circ} \mathrm{C}$ for 72 hours. Laboratory reference clones, 3D7, regarded as chloroquine sensitive and DD2 classified as chloroquine resistant, were assayed periodically as internal control.

Assessment of the outcome of the in vitro drug test was done using the SYBR Green1 method previously described by Johnson and colleagues [14]. In brief, after 72 hours of incubation, the test plate was removed and $100 \mu \mathrm{l}$ Malaria SYBR Green 1 fluorescent (MSF) lysis buffer containing SYBR Green was added to each well and mixed thoroughly by gently tapping on the plate. The plate was covered with aluminium foil and incubated at room temperature in the dark for at least two hours. Fluorescence was then read on the prototype micro titer plate reader (MTPR) (QIAGEN).

\section{Data analysis}

The concentration of anti-malarial drug inhibiting parasite growth by $50 \%\left(\mathrm{IC}_{50}\right)$ for each drug was estimated from a dose response curve by non-linear regression analysis using an online program [16] previously described by the groups of Le Nagard and Kaddouri $[17,18]$. The program generated $\mathrm{IC}_{50}$ estimates with associated 95\% confidence intervals (CI). Estimated values with insufficient precision based on the $\mathrm{CI}$ were discarded. Geometric mean (GM) $\mathrm{IC}_{50}$ was calculated for each drug per sentinel site and a pooled national GM $\mathrm{IC}_{50}$ valued was also determined. The use of $\mathrm{GM}$ was to minimize the effects of outlier values. In order to check for evidence of cross resistance, a Spearman's Rank Order correlation was run to determine the relationship between drugs with similar modes of action or for those belonging to the same chemical class. A p-value of 0.05 was considered indicative of a statistically significant 
relation. Scatter graph and bar charts were used to present some of the results.

\section{Results}

Majority of the children clinically diagnosed with malaria and confirmed by microscopy to have an infection with P. falciparum qualified to participate in the study. Sixty three clinical isolates were collected within one month per site. Over 85\% of the 189 P. falciparum clinical isolates collected from the three selected sentinel sites were successfully cultured and their susceptibilities to the test anti-malarial drugs determined.

The outcome of the test of susceptibilities of clinical isolates of $P$. falciparum collected from three sentinel sites in Ghana is shown in Additional file 1: Table S1. When the values for all the study sites were pooled, the $\mathrm{GM} \mathrm{IC} 50$ values determined for the country were 1.60 , $3.80,4.00,4.56,5.20,6.11,10.12,28.32,31.56,93.60$, 107.20, and $8952.50 \mathrm{nM}$ for atovaquone, artesunate, dihydroartemisin, artemether, lumefantrine, amodiaquine, mefloquine, piperaquine, chloroquine, tafenoquine, quinine, and doxycycline, respectively. Extremely high $\mathrm{IC}_{50}$ values were observed for some of the anti-malarial drugs; for example, values of $1441.8 \mathrm{nM}, 109.4 \mu \mathrm{M}, 125.9 \mathrm{nM}$ and $6381.9 \mathrm{nM}$ which are far above the threshold $\mathrm{IC}_{50}$ values discriminative for resistance were measured for chloroquine, doxycycline, mefloquine, and quinine, respectively. Generally, the isolates from Cape Coast appeared to exhibit higher $\mathrm{IC}_{50}$ values to most of the drugs compared to those from the other sites.

A snapshot of a scatter plot of $\mathrm{IC}_{50}$ values for six of the popular anti-malarial drugs used in Ghana is shown in Figure 2 (a-e). The percentage of the isolates that were resistant for each of the anti-malarial drugs tested per site based on published threshold $\mathrm{IC}_{50}$ values discriminative for resistance is also shown in Additional file 1 : Table S1. The literature $\mathrm{IC}_{50}$ cut-off value indicative of resistance used in this study were chloroquine, $100 \mathrm{nM}$ [19-21]; mefloquine, $30 \mathrm{nM}$ [19,21,22]; amodiaquine, 80 $\mathrm{nM}$ [20-22]; lumefantrine, $150 \mathrm{nM}$ [21,23]; doxycycline, $35 \mu \mathrm{M}$ [21]; artesunate, $20 \mathrm{nM}$ [21]; quinine, $800 \mathrm{nM}$ [20,22]; dihydroartemisinin, $12 \mathrm{nM}$ [21] and artemether, $30 \mathrm{nM}[21,24]$. Cut-off resistant values for piperaquine and tafenoquine were not available in the literature. It is worth noting that prior to the emergence of atovaquone resistance, Gay and colleagues published a cut-off value of 5-7 nM for resistance [25]. However, upon the emergence of $P$. falciparum resistance to atovaquone, the group of Musset revised the cut-off to $1,900 \mathrm{nM}$ after investigations using resistant phenotype [26]. For the drugs with known literature threshold $\mathrm{IC}_{50}$ values indicative of resistance, the determined levels of resistance recorded in this study were $13.5,16.6,3.7,0.7,23.7,0$, $7.1,0,0$, and $0 \%$ for chloroquine, mefloquine, amodiaquine, lumefantrine, doxycycline, artesunate, quinine, dihydroartemisinin, artemether, and atovaquone, respectively.

Although the radio-isotopic method was used in determining the cut-off values indicative of resistance, it must be emphasised that the $\mathrm{IC}_{50}$ values generated with the Sybr Green 1fluorescence method is reported to be comparable. Smilkstein and co-workers reported that the $\mathrm{IC}_{50}$ of standard anti-malarial drugs determined with both radio-isotopic and Sybr Green methods were similar or identical [27]. Although the group of Johnson also reported a similar observation, however the group admitted that a statistically significant difference exist between $\mathrm{IC}_{50}$ values generated between the two assays [13]. The group however found the sensitivity index to be the same for the two methods, suggesting that although statistically significant differences do exist between the two assays, they are likely not biologically significant[13].

Figure 3 shows the trend in in vitro responses of Ghanaian P. falciparum isolates to chloroquine between 1990 and 2012. Resistance to chloroquine in vitro increased from 1990 to an all-time high in 2004 and decreased significantly in 2012. Figure 4 (a-e) shows the comparison of $\mathrm{IC}_{50}$ value of some of the popularly used anti-malarial drugs in Ghana before the change in treatment policy (2004) and the current report (2012). There was a drastic reduction in $\mathrm{IC}_{50}$ values for chloroquine determined in 2012 compared with that of 2004: more than $50 \%$ decrease in the pooled national $\mathrm{GM} \mathrm{IC}_{50}$ values between the two dates. Compared to the data from the 2004 survey, the current results showed a moderate increase in $\mathrm{GM} \mathrm{IC}_{50}$ value for artesunate and a high increase for quinine and mefloquine.

The level of correlation between the $\mathrm{IC}_{50} \mathrm{~s}$ of some of the anti-malarial drugs studied per sentinel site is shown in Additional file 2: Table S2. A p-value of $<0.05$ was considered as the threshold indicative of a statistically significant correlation. Significant correlation was found among the following pairs of drugs: amodiaquine versus quinine (at Cape Coast); artemether versus dihydroartemisinin (at Cape Coast and Hohoe); chloroquine versus quinine (at Hohoe); amodiaquine versus mefloquine (at Hohoe); mefloquine versus quinine (at Navrongo).

To ensure that the reagents or drugs used in this study maintained their quality throughout the study period, 3D7 and DD2 clone of P. falciparum was tested fortnightly against known drugs and the $\mathrm{IC}_{50}$ values obtained compared with universally acceptable values for the drugs.

\section{Discussion}

In vitro assessment of the susceptibility of malaria parasites to drugs remains an important component of antimalarial drug efficacy surveillance. Since this method is 


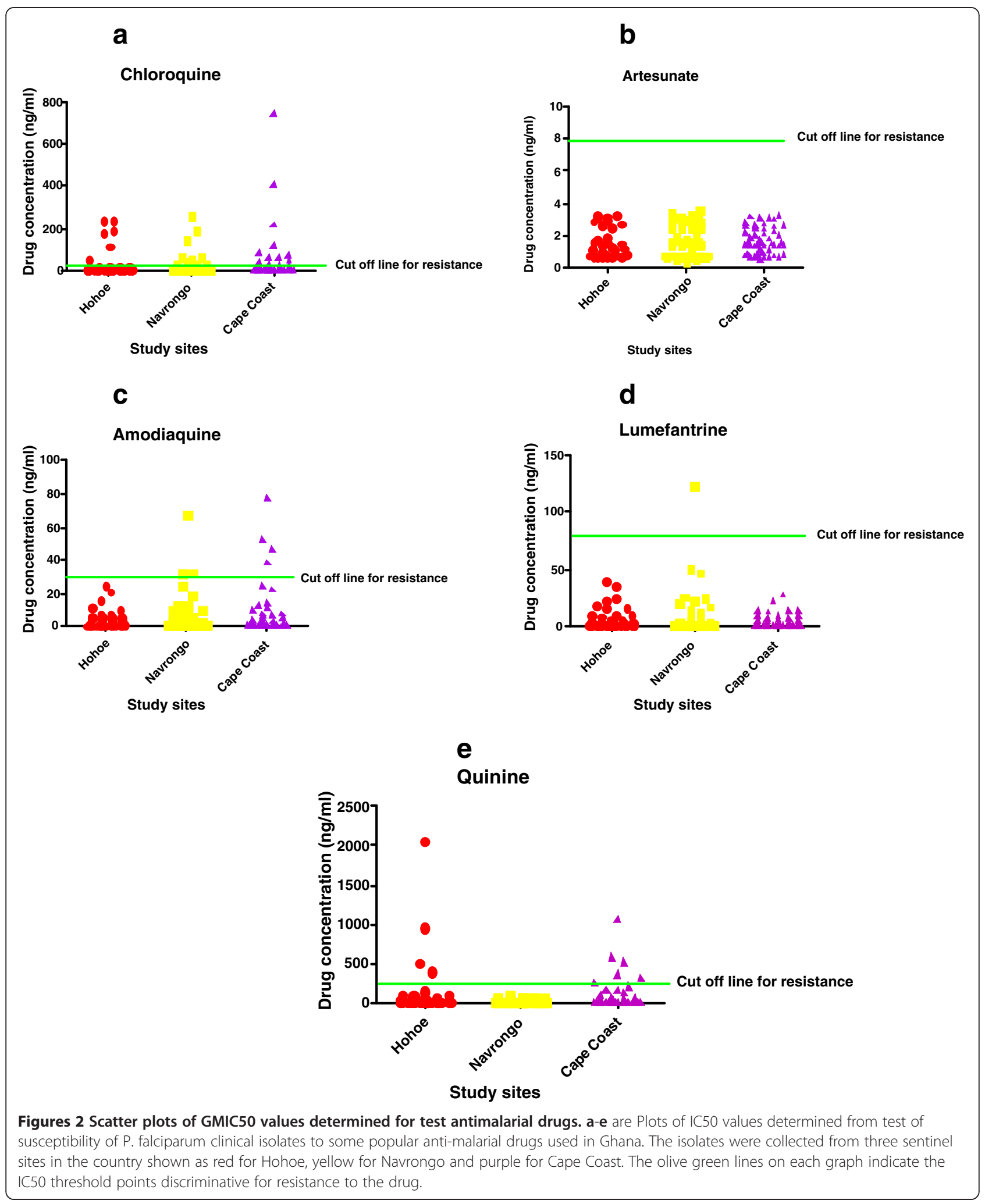

largely independent of clinical factors, it provides information that complements clinical assessment of drug efficacy. The SYBR Green1 method of assessing the outcome of the in vitro drug test was revalidated and used to assess the responses of $P$. falciparum clinical isolates to a panel of 12 anti-malarial drugs in Ghana. To the best of 


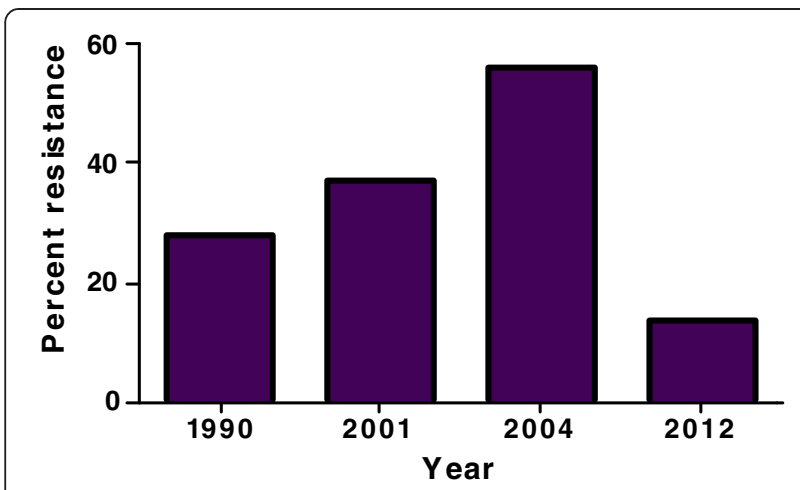

Figure 3 Trends in chloroquine resistance in vitro in Ghana.

Trends in resistance of Ghanaian $P$. falciparum isolates to chloroquine in vitro from 1990 through $2012[15,28,29]$. The number of isolates assessed was 195, 64, 57, and 141 for the year 1990, 2001, 2004 and 2012 respectively. NB: the current report is shown in the chart as 2012

knowledge, this is the first use of the SYBR Green 1 method in Ghana and the reported assertion that it is easy to use, reliable and cheaper could be affirmed. All the components of ACT currently used in Ghana as well as quinine and the previous first-line anti-malarial drug, chloroquine were among the test drugs.

Compared with findings from a similar survey conducted in 2004 [15], the overall resistance to chloroquine determined in this study dropped drastically from 56 to $13.5 \%$. A pooled national $\mathrm{GM} \mathrm{IC}_{50}$ of chloroquine was also observed to have decreased by more than $50 \%$ compared to the 2004 value. These observations are consistent with reports from East African countries, Malawi and Kenya, indicating the return of chloroquine-sensitive isolates following a similar official withdrawal of the drug [30-32]. It also confirms an observation made in a study conducted in France using isolates collected from returning visitors from Senegal, Mali, Ivory Coast, and Cameroon [33]. The large improvement in the efficacy of chloroquine observed in the present study is important as it seems to reflect the real situation on the ground. Indeed, this gives credence to recent finding in Ghana indicating a significant decline in the prevalence of $P$. falciparum chloroquine-resistant transporter gene (pfcrt) codon76 mutant allele (T76) and $P$. falciparum multidrug-resistant gene (pfmdr1) codon 86 mutant allele (Y86) in the country [34]. Prevalence of pfcrt T76 mutation has been associated with clinical chloroquine resistance and represents a good indicator of the parasite's intrinsic resistance to the drug [35,36]. Additionally, single nucleotide polymorphisms (SNPs) in the $p f m d r 1$ on chromosome 5 which encodes a P-glycoprotein homologue-1 multi-drug resistant transporter is associated with enhanced efflux of the drug from resistant parasites [37]. Association of chloroquine resistance with pfmdr1 Y86 has been reported in many genetic studies including one carried out in Ghana by the group of Koram [38,39]. Eight years have elapsed since chloroquine was replaced with $\mathrm{ACT}$ as the firstchoice anti-malarial drug in Ghana. It is, therefore, likely that the withdrawal of chloroquine from use over these years might have caused a decrease in drug pressure with a consequent decline of chloroquineresistant strains.

Currently, AA is one of the officially recommended ACT selected for treatment of uncomplicated malaria in Ghana. The combination is also used for the treatment of uncomplicated malaria in the second and third trimester of pregnancy and is recommended for the assisted home management of malaria in Ghana [40]. Although all the isolates tested in this study appear to be sensitive to artesunate, of grave concern is the increased pooled national $\mathrm{GM} \mathrm{IC}_{50}$ value measured in this study compared with that of 2004. This observation suggests an emerging population of malaria parasites with tolerance for higher concentrations of artesunate. One explanation could be selective drug pressure since ACT is now the first line of therapy for uncomplicated malaria. However, another possible explanation may be that artesunate is being used inappropriately in the country thus facilitating the development of 'low level resistance' by malaria parasites. Published data by Kwansa-Bentum and colleagues confirms the indiscriminate use of artesunate monotherapy for the treatment of malaria in Ghana [41]. The consequences of continuation of this practice are obvious. There is the need to adhere strictly to the current national treatment guidelines which are in conformity with the WHO guidelines as endorsed by the World Health Assembly [42-44]. Recently, a new method for the assessment of the response of P.falciparumin to the artemisinins in vitro was developed. This is in response to reports suggesting that artemisinin resistant parasites tolerate high levels of the drug by exiting dormancy and resuming growth at a greater rate than susceptible parental strains [45]. This situation makes it difficult to evaluate the in vitro activity of the artemisinin derivatives by standard tests. In the light of this, a new method called the Ring-stage Survival Assay (RSA)' which is supposed to adequately measure $P$. falciparum resistance to the aremisinins was developed and published by Witkowski and co-workers [46]. With regard to amodiaquine, there was no significant change in the $\mathrm{GM} \mathrm{IC}_{50}$ value determined in this study compared to the 2004 value. However, a few of the P. falciparum isolates were observed to be resistant to the drug in vitro. Amodiaquine is chemically related to chloroquine, and it is not extensively used in Ghana for monotherapy. The high susceptibility of the parasite to amodiaquine observed in the present study might be explained both by 


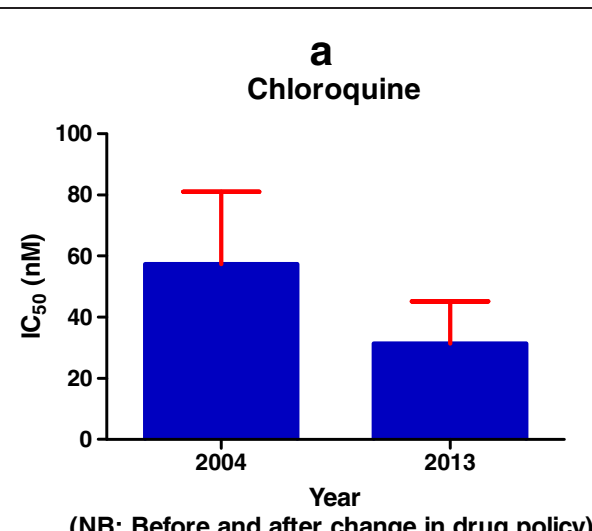

(NB: Before and after change in drug policy)

C

Quinine

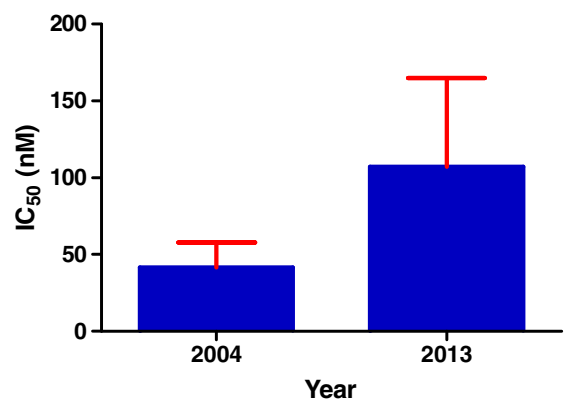

(NB: Before and after change in drug policy)

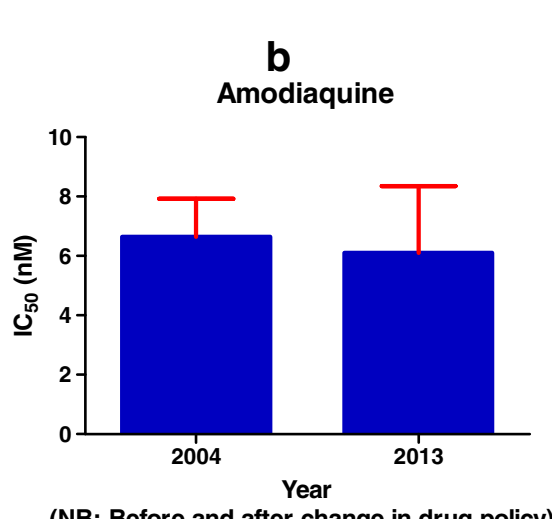

(NB: Before and after change in drug policy)

d

Artesunate

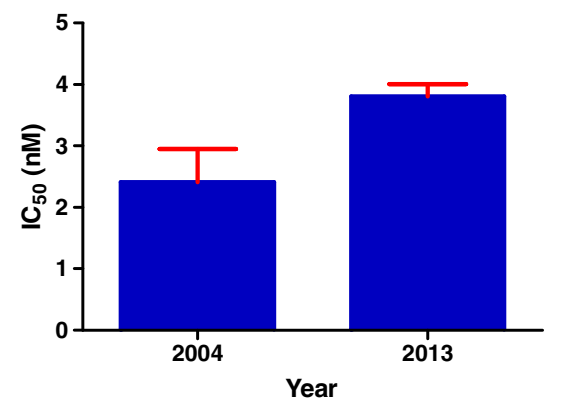

(NB: Before and after change in drug policy)

e

Mefloquine

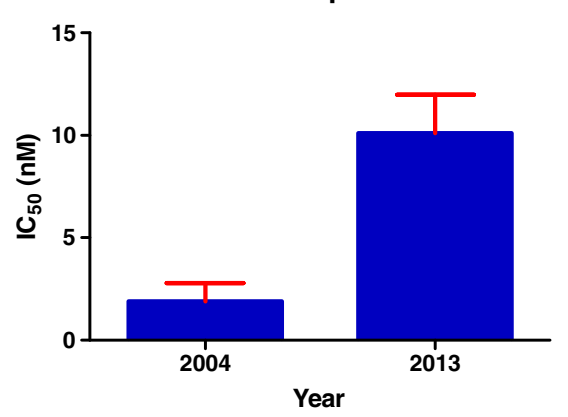

(NB: Before and after change in drug policy)

Figures 4 Comparison between GMIC50 values of antimalarial drugs. The GM IC50 values of some selected anti-malarial before (2004) and eight years after (2012) the change in malaria treatment policy in Ghana were compared. The comparison is shown in a-e of the figure for chloroquine, amodiaquine, quinine, artesunate and mefloquine respectively. The error bars are the standard error of the mean.

the decline in chloroquine-resistant isolates discussed earlier and/or the switch from amodiaquine monotherapy to AA combination therapy: the combination might have offered protection to amodiaquine and precipitated the improvement or stability of amodiaquine and chloroquine susceptibility. The stability in potency justifies the continuous use of amodiaquine as a component of the official ACT.

Artemether-lumefantrine combination was recommended as an alternative for the treatment of uncomplicated malaria in Ghana following reports of adverse reaction to AA [47]. All the $P$. falciparum isolates tested in this study were susceptible to artemether with an overall national $\mathrm{GM} \mathrm{IC}_{50}$ value of $4.5 \mathrm{nM}$. The isolates also responded to lumefantrine with a pooled national $\mathrm{GM} \mathrm{IC}_{50}$ value of $5.2 \mathrm{nM}$. Based on the literature cut-off for resistance, only one isolate showed resistance to lumefantrine. There is no baseline in vitro data on these two drugs in Ghana hence the changes that might have occurred in their efficacy since the change in the treatment policy could not be discussed. However, compared 
with published data from studies conducted in other countries, the $\mathrm{IC}_{50}$ values of the drugs measured in the present study are much lower.

Combination of dihydroartemisinin and piperaquine is another form of ACT recommended for the treatment of uncomplicated malaria in Ghana. All the isolates assessed in this study were sensitive to dihydroartemisinin. Since the former is the active metabolite of artesunate, the result was not surprising. No correlation indicative of cross-resistance was found between artesunate and dihydroartemisinin. Resistance level of piperaquine could not be ascertained in this study due to the unavailability of literature cut-off $\mathrm{IC}_{50}$ value indicative of resistance to the drug.

A geometric mean $\mathrm{IC}_{50}$ value of $107.2 \mathrm{nM}$ determined for quinine is more than double that reported in 2004 . Furthermore, unlike in 2004, some of the isolates tested in this study were resistant to the drug. Quinine is an important anti-malarial drug in Ghana as it remains the drug of choice for the management of complicated malaria and in the event of ACT treatment failure. Oral quinine or a combination of oral quinine and clindamycin is also the recommended drug for the management of uncomplicated malaria during the first trimester of pregnancy in Ghana [47]. Since this drug is not used on a regular basis in Ghana, a clear explanation for the decrease in parasite susceptibility to the drug observed in vitro is not easy to come by. However, it is noteworthy that in surveys of drug quality in sub-Saharan Africa, quinine has often been found to be sub-standard, including samples with low concentrations of active ingredient [48]. The use of sub-standard drug is likely to jeopardize the efficacy of the anti-malarial drug.

Mefloquine and atovaquone are recommended drugs for non-immune travellers for chemoprophylaxis. Even though the pooled $\mathrm{GM} \mathrm{IC}_{50}$ determined in this study for mefloquine was far below the cut-off value discriminative for resistance, about $16.6 \%$ of the $P$. falciparum isolates assessed were resistant to the drug. Compared with the level observed in the 2004 study, the $\mathrm{IC}_{50}$ measured here is over five-fold increase. Mefloquine, which belongs to the amino-alcohol class, is not used much in Ghana, hence drug pressure could not explain the increase in resistance. However, since some in vitro studies have demonstrated an inverse relationship between the responses of chloroquine and the amino-alcohols $[49,50]$ this phenomenon could best explain the observation. All the $P$. falciparum isolates tested in this study were sensitive to atovaquone.

Tafenoquine, an 8-aminoquinoline anti-malarial drug, which was recently introduced to the world market, represents a potential alternative to standard agents for the prevention and radical cure of malaria [51]. In the absence of an available literature cut-off value indicative of resistance, the $\mathrm{GM} \mathrm{IC}_{50}$ value of $93.6 \mathrm{nM}$ obtained in this study was compared with those determined in other countries. The $\mathrm{IC}_{50}$ values reported from other countries range from 0.9 to $9.7 \mu \mathrm{M}$ in Djibouti, 0.6 to $33.1 \mu \mathrm{M}$ in Gabon, and 0.5 to $20.7 \mu \mathrm{M}$ in Senegal [52]. Compared with these values, the pooled national $\mathrm{GM} \mathrm{IC}_{50}$ value of 93.6 $\mathrm{nM}$ determined in this study is relatively low and implies that Ghanaian P. falciparum isolates are highly sensitive to the drug.

The anti-malarial activity of tetracycline and its derivatives has been demonstrated in vitro and in vivo [53-55]. Currently doxycycline is recommended as chemoprophylaxis to non-immune travellers to some disease-endemic countries of the world. Doxycycline is also used generally as an antibiotic for the management of a variety of infection such as Lyme disease, acne, urinary tract infections, and pneumonia, among others. However, information on its use in Ghana both as an anti-malarial drug or antibiotic is scanty. In the present study, doxycycline had the least effect on the clinical isolates tested, showing a resistance level of above $20 \%$. The observed high resistance to the drug could be explained in terms of its mechanism of action. A study by Dahl and Rosenthal showed that the pharmacological concentration of the drug was relatively inactive against the parasites initially but exerted a delayed death effect, in which the progeny of treated parasites failed to complete erythrocytic development [56]. The report further indicated that the drug does not alter the distribution of apicoplasts in developing parasites but affects their progeny. This implies that a longer period of exposure is required to achieve maximum effect of doxycycline. Since in the present study the parasites were cultured for only 72 hours, the duration of the culture may be insufficient and could be the reason for the slow anti-malarial action of doxycycline observed in this study. An extended time of incubation to 96 hours would have ensured adequate effect of the drug on the parasite and would have presented a better picture of the Ghanaian P. falciparum isolate's susceptibility to doxycycline.

An important observation made in this study was that the P. falciparum isolates from Cape Coast exhibited higher $\mathrm{IC}_{50}$ values compared to those from the other sites. Environmental and socio-economic factors could be possible reasons for this observation. The site in Cape Coast receives most of its clients from communities with poor infrastructural development. The presence of stagnant water in these communities might contribute greatly to mosquito breeding and an increase in malaria transmission. This situation is likely to lead to increased anti-malarial use in this area. Indeed, an unpublished investigation by the group of Johnson Boampong (University of Cape-Coast, Ghana) confirmed the indiscriminate use of anti-malarial drugs in the study area (Kwame Asare Kumi, pers comm). This 
practice is likely to lead to increased drug pressure with a consequent selection and nurturing of resistant parasites.

Cross-resistance could be said to occur when a drug confers resistance to other drugs that have similar mode of action or belong to the same chemical group. Crossresistance may complicate anti-malarial drug resistance, and its existence is worth investigating. A positive correlation between the responses to two anti-malarial drugs suggests an in vitro cross-resistance but not necessarily confer cross-resistance in vivo. In the present study, the existence of cross-resistance among some of the test drugs was ascertained. A positive correlation was found between the $\mathrm{IC}_{50}$ values for: amodiaquine and quinine, artemether and dihydroartemisinin, chloroquine and quinine, amodiaquine and mefloquine, and mefloquine and quinine. All the observed significant correlations were limited to one site except that between artemether and dihydroartemisinin where it was observed in two of the three sites surveyed. It is worth noting that a significant correlation between two drugs tested in vitro doesn't necessary mean a cross resistance exist among them. For a correlation to imply that two compounds share common mechanisms of action or resistance, which could induce cross-resistance, the coefficient of determination $\left(\mathrm{r}^{2}\right)$ must be high. In this study, the $r^{2}$ values of the drugs showing significant correlation were too low to suggest a strong cross-resistance between them. Contrary to expectation, no positive correlation was observed between artesunate and artemether or dihydroartemisin. A possible explanation for this observation could be the usage of a single ACT in the study areas: artesunate amodiaquine combination is the most widely used ACT in these communities. Significant correlation between some of these drugs may be explained in part by close resemblance in chemical structures. It must be emphasized that clinical and epidemiological significance or implications of the correlation between some of the anti-malarial drugs observed in this study will be difficult to decipher.

Delayed clearance of $P$. falciparum isolates with ACT has recently been reported [8]. The emergence of $P$. falciparum resistance to artemisinin derivatives is of urgent public health concern, which could considerably slow down the global effort to reduce the malaria burden. In the absence of an effective malaria vaccine, steps must be taken to protect the artemisinin derivatives. In the light of this, the WHO has launched the Global Plan for Artemisinin Resistance Containment (GPARC) aimed at avoiding the spread of resistance from the area of first report of resistance to other disease-endemic zones [57]. In Ghana, various measures have been taken by the NMCP to avoid the emergence of drug resistance to ACT; sentinel sites have been set up across the country to monitor the efficacy of ACT. However, with the observations made in this study, the need to adopt a more aggressive approach must be considered. The NMCP needs to launch a more vigorous national campaign against improper use of the artemisinin derivatives. Equally important is drug quality: steps must be taken to eliminate counterfeit ACT and reduce sub-standard manufacturing with lower concentration of artemisinin content. The entire pharmaceutical distribution modes and drug supply chains that impact directly on drug use must be purged to ensure the supply of good quality drugs and the total enforcement of the ban on certain anti-malarial drugs such as chloroquine, or cessation of practices such as the use of the artemisinin derivatives as monotherapy. With the validation and subsequent use of the SYBR Green method in Ghana, continuous assessment of the susceptibility of $P$. falciparum to anti-malarial drugs in the country must be encouraged in order to make available to the NMCP supportive data that will allow prediction of emerging resistant strains of parasites in the country.

\section{Conclusion}

Given the lack of robust molecular markers predictive of anti-malarial resistance for the artemisinins and the huge cost in conducting in vivo efficacy study, the in vitro method of assessment of the artemisinins and other antimalarial drugs is warranted. The in vitro method was successfully used to assess the sensitivity of Ghanaian $P$. falciparum isolates to 12 anti-malarial drugs. Although frank resistance to artesunate was not observed, a concerning trend of increasing $\mathrm{GMIC}_{50}$ since the introduction of ACT was noticed. This situation warrants continuous monitoring of ACT. On the other hand, chloroquine appears to have regained a greater proportion of its efficacy after being out of use as first-line drug for eight years.

\section{Additional files}

Additional file 1: Table S1. In vitro drug susceptibility of Plasmodium falciparum isolates to 12 anti-malarial drugs. The drug sensitivities of the isolates collected from clinics in three sentinel sites in Ghana were assessed using the SYBR Green 1 method and the results presented below. Proportion of $P$. falciparum clinical isolates per sentinel site that were resistant to the anti-malarial drugs tested, based on literature cut-off $I_{50}$ values (last column) is also shown.

Additionalo file 2: Table S2. Cross-resistance between test anti-malarial drugs. Degree of correlation ( $r$ ) between the $I_{50}$ s of some of the test anti-malarial drugs per sentinel site using Spearman's rank order correlation. The statistical significance of the correlation is also indicated. A p-value of $<0.05$ was considered indicative of statistically significant correlation.

\section{Competing interests}

The authors have no competing interest to declare. None of the authors received any remuneration for this work. 


\section{Authors' contributions}

$\mathrm{KCK}, \mathrm{NBQ}, \mathrm{NWL}, \mathrm{VU}$ and KAK conceived the idea and worked with BA, NOD, $J D J, C D$, and $M K$ on the design and data acquisition. NBQ, GAA, RA, MK, NOD, BA and LQ coordinated the field or laboratory work. NBQ drafted the manuscript. All authors participated in the revisions of the manuscript and gave approval for the final version for publication.

\section{Acknowledgements}

The Global Emerging Infections Surveillance and Response System (GEIS), a Division of the Armed Forces Health Surveillance Center (AFHSC) [Project no. C0437_11_N3] funded this work. WWARN is acknowledged for providing the anti-malarial drugs used in this study. We also thank CDC for donating a field-based customized fluorescence plate reader for the project and training. We thank Dr Jacob Johnson and Mr Hosea Akala (Department of Emerging Infectious Diseases Program, US Army Medical Research Unit-Kenya, Kenya Medical Research Institute-Walter Reed Project, Kisumu, Kenya) for training the NMIMR Group on the use of the SYBR Green method. We also thank the teams in Hohoe Municipal Hospital, Likpe-Bakwa Health Centre, Navrongo War Memorial Hospital, Ewim Health Centre, Cape Coast and Central Regional Hospital. We acknowledge the cooperation of the Navrongo Health Research. The sentinel sites were originally set up by the Noguchi Memorial Institute for Medical Research in collaboration with the NMCP and supported financially with the Global Fund.

\section{Author details}

${ }^{1}$ Centre for Tropical Clinical Pharmacology and Therapeutics, University of Ghana Medical School, Accra, Ghana. ${ }^{2}$ Epidemiology Department, Noguchi Memorial Institute for Medical Research, University of Ghana, Accra, Ghana.

${ }^{3}$ US Naval Medical Research Unit No. 3, Cairo, Egypt. ${ }^{4}$ Hohoe Health Research Centre, Hohoe, Ghana. ${ }^{5}$ Department of Emerging Infectious Diseases Program, US Army Medical Research Unit-Kenya, Kenya Medical Research Institute-Walter Reed Project, Kisumu, Kenya. ${ }^{6}$ Division of Parasitic Diseases and Malaria, Center for Global Health, Centers for Disease Control and Prevention, Atlanta, Georgia, USA.

Received: 4 October 2013 Accepted: 10 December 2013

Published: 17 December 2013

\section{References}

1. WHO: World Malaria Report, 2012. Geneva: World Health Organization; 2013.

2. RBM: Regional Strategies. 2013. http://www.rollbackmalaria.org/gmap/ part3.pdf.

3. MOH: Malaria report, 2008. Ghana: Ministry of Health; 2009.

4. Ahmed K: Malaria in Ghana-overview. Ghana Med J 1989, 22:190-196.

5. Chinnock P: Malaria, action at last. Afr Health Sci 1997, 19:12-13.

6. NMCP: Annual Report of the National Malaria Control Programme of Ghana, 2005. Ghana: Ministry of Health; 2006.

7. Koram KA, Abuaku B, Duah N, Quashie N: Comparative efficacy of antimalarial drugs including ACTs in the treatment of uncomplicated malaria among children under 5 years in Ghana. Acta Trop 2005, 95:194-203.

8. Dondorp AM, Nosten F, Yi P, Das D, Phyo AP, Tarning J, Lwin KM, Ariey F, Hanpithakpong W, Lee SJ, Ringwald P, Silamut K, Imwong M, Chotivanich K, Lim P, Herdman T, An SS, Yeung S, Singhasivanon P, Day NP, Lindegardh N, Socheat D, White NJ: Artemisinin resistance in Plasmodium falciparum malaria. N Engl J Med 2009, 361:455-467.

9. Briolant S, Baragatti M, Parola P, Simon F, Tall A, Sokhna C, Hovette P, Mamfoumbi MM, Koeck JL, Delmont J, Spiegel A, Castello J, Gardair JP, Trape JF, Kombila M, Minodier P, Fusai T, Rogier C, Pradines B: Multi normal in vitro distribution model suitable for the distribution of Plasmodium falciparum chemo-susceptibility to doxycycline. Antimicrob Agents Chemother 2009, 53:688-695.

10. Ringwald P: Assessment and Monitoring of Antimalarial Drug Efficacy for the Treatment of Uncomplicated Falciparum Malaria. Geneva, Switzerland: World Health Organization; 2003.

11. Bacon DJ, Latour C, Lucas C, Colina O, Ringwald P, Picot S: Comparison of a SYBR green I-based assay with a histidine-rich protein II enzyme-linked immunosorbent assay for in vitro antimalarial drug efficacy testing and application to clinical isolates. Antimicrob Agents Chemother 2007, 51:1172-1178
12. Bacon DJ, Jambou R, Fandeur T, Le BJ, Wongsrichanalai C, Fukuda MM, Ringwald P, Sibley $\mathrm{CH}$, Kyle DE: World antimalarial resistance network (WARN) II: in vitro antimalarial drug susceptibility. Malar J 2007, 6:120.

13. Yavo W, Bla KB, Djaman AJ, Assi SB, Basco LK, Mazabraud A, Kone M: In vitro susceptibility of Plasmodium falciparum to monodesethylamodiaquine, quinine, mefloquine and halofantrine in Abidjan (Cote d'Ivoire). Afr Health Sci 2010, 10:111-116.

14. Johnson JD, Dennull RA, Gerena L, Lopez-Sanchez M, Roncal NE, Waters NC: Assessment and continued validation of the malaria SYBR green I-based fluorescence assay for use in malaria drug screening. Antimicrob Agents Chemother 2007, 51:1926-1933.

15. Quashie NB, Duah NO, Abuaku B, Koram KA: The in-vitro susceptibilities of Ghanaian Plasmodium falciparum to antimalarial drugs. Ann Trop Med Parasitol 2007, 101:391-398.

16. ICEstimator (version 1.2). http://www.antimalarialicestimator.net/ Methodlntro.htm.

17. Kaddouri H, Nakache S, Houze S, Mentre F, Le BJ: Assessment of the drug susceptibility of Plasmodium falciparum clinical isolates from Africa by using a Plasmodium lactate dehydrogenase immunodetection assay and an inhibitory maximum effect model for precise measurement of the 50percent inhibitory concentration. Antimicrob Agents Chemother 2006, 50:3343-3349.

18. Le NH, Vincent C, Mentre F, Le BJ: Online analysis of in vitro resistance to antimalarial drugs through nonlinear regression. Comput Methods Programs Biomed 2011, 104:10-18.

19. Brasseur P, Kouamouo J, Moyou RS, Druilhe P: Emergence of mefloquine-resistant malaria in Africa without drug pressure. Lancet 1990, 336:59.

20. Dedet JP, Germanetto P, Cordoliani G, Bonnevie O, Le BJ: [In vitro activity of various antimalarials (chloroquine, amodiaquine, quinine and mefloquine) against 32 isolates of Plasmodium falciparum in French Guiana](in French). Bull Soc Pathol Exot Filiales 1988, 81:88-93.

21. Pradines B, Bertaux L, Pomares C, Delaunay P, Marty P: Reduced in vitro susceptibility to artemisinin derivatives associated with multi-resistance in a traveller returning from South-East Asia. Malar J 2011, 10:268.

22. Reynes JM, Fargette J, Gaborit P, Yarde S: In vitro responses of Plasmodium falciparum isolates to five antimalaria drugs in French Guiana during 1994 and 1995. Mem Inst Oswaldo Cruz 1997, 92:251-252.

23. Mungthin M, Khositnithikul R, Sitthichot N, Suwandittakul N, Wattanaveeradej V, Ward SA, Na-Bangchang K: Association between the pfmdr1 gene and in vitro artemether and lumefantrine sensitivity in Thai isolates of Plasmodium falciparum. Am J Trop Med Hyg 2010, 83:1005-1009.

24. Hunt P, Afonso A, Creasey A, Culleton R, Sidhu AB, Logan J, Valderramos SG, McNae I, Cheesman S, Do RV, Carter R, Fidock DA, Cravo P: Gene encoding a deubiquitinating enzyme is mutated in artesunate- and chloroquine-resistant rodent malaria parasites. Mol Microbiol 2007, 65:27-40.

25. Gay F, Bustos D, Traore B, Jardinel C, Southammavong M, Ciceron L, Danis MM: In vitro response of Plasmodium falciparum to atovaquone and correlation with other antimalarials: comparison between African and Asian strains. Am J Trop Med Hyg 1997, 56:315-317.

26. Musset L, Pradines B, Parzy D, Durand R, Bigot P, Le Bras J: Apparent absence of atovaquone/proguanil resistance in 477 Plasmodium falciparum isolates from untreated French travellers. J Antimicrob Chemother 2006, 57:110-115.

27. Afari EA, Akanmori BD, Nakano T, Ofori-Adjei D: In vitro responses of Plasmodium falciparum parasites to chloroquine, amodiaquine and quinine in two ecological zones in Ghana. Cent Afr J Med 1993, 39:136-140.

28. Smilkstein M, Sriwilaijaroen N, Kelly JX, Wilairat P, Riscoe M: Simple and inexpensive fluorescence-based technique for high-throughput antimalarial drug screening. Antimicrob Agents Chemother 2004, 48:1803-1806.

29. Quashie NB, Ofori-Adjei D, Duah NO, Koram K: In vitro susceptibility of Plasmodium falciparum isolates to chloroquine and other antimalarial drugs in Ghana. Ghana Med J 2004, 38:131-135.

30. Kublin JG, Cortese JF, Njunju EM, Mukadam RA, Wirima JJ, Kazembe PN, Djimde AA, Kouriba B, Taylor TE, Plowe CV: Re-emergence of chloroquine-sensitive Plasmodium falciparum malaria after cessation of chloroquine use in Malawi. J Infect Dis 2003, 187:1870-1875.

31. Laufer MK, Thesing PC, Eddington ND, Masonga R, Dzinjalamala FK, Takala SL, Taylor TE, Plowe CV: Return of chloroquine antimalarial efficacy in Malawi. $N$ Engl J Med 2006, 355:1959-1966. 
32. Mwai L, Ochong E, Abdirahman A, Kiara SM, Ward S, Kokwaro G, Sasi P, Marsh K, Borrmann S, Mackinnon M, Nzila A: Chloroquine resistance before and after its withdrawal in Kenya. Malar J 2009, 8:106.

33. Gharbi M, Flegg JA, Hubert V, Kendjo E, Metcalf JE, Bertaux L, Guerin PJ, Le BJ, Aboubaca A, Agnamey P, Angoulvant A, Barbut P, Basset D, Belkadi G, Bellanger AP, Bemba D, Benoit-Vica F, Berry A, Bigel ML, Bonhomme J, Botterel F, Bouchaud O, Bougnoux ME, Bouree P, Bourgeois N, Branger C, Bret $L$, Buret $B$, Casalino $E$, Chevrier $S$, et al: Longitudinal study assessing the return of chloroquine susceptibility of Plasmodium falciparum in isolates from travellers returning from West and Central Africa, 2000-2011. Malar J 2013, 12:35.

34. Duah NO, Wilson MD, Ghansah A, Abuaku B, Edoh D, Quashie NB, Koram KA: Mutations in Plasmodium falciparum chloroquine resistance transporter and multidrug resistance genes, and treatment outcomes in Ghanaian children with uncomplicated malaria. J Trop Pediatr 2007, 53:27-31.

35. Djimde A, Doumbo OK, Cortese JF, Kayentao K, Doumbo S, Diourte Y, Coulibaly D, Dicko A, Su XZ, Nomura T, Fidock DA, Wellems TE, Plowe CV: A molecular marker for chloroquine-resistant falciparum malaria. $N$ Engl JMed 2001, 344:257-263.

36. Fidock DA, Nomura T, Talley AK, Cooper RA, Dzekunov SM, Ferdig MT, Ursos LM, Sidhu AB, Naudé B, Deitsch KW, Su XZ, Wootton JC, Roepe PD, Wellems TE: Mutations in the $P$. falciparum digestive vacuole transmembrane protein PFCRT and evidence for their role in chloroquine resistance. $\mathrm{Mol}$ Cel 2000, 6:861-871.

37. Foote SJ, Kyle DE, Martin RK, Oduola AM, Forsyth K, Kemp DJ, Cowman AF: Several alleles of the multidrug-resistance gene are closely linked to chloroquine resistance in Plasmodium falciparum. Nature 1990, 345:255-258.

38. Duah NO, Matrevi SA, de Souza DK, Binnah DD, Tamakloe MM, Opoku VS, Onwona CO, Narh CA, Quashie NB, Abuaku B, Duplessis C, Kronmann KC, Koram KA: Increased pfmdr1 gene copy number and the decline in pfcrt and pfmdr1 resistance allelles in Ghanaian Plasmodium falciparum isolates after the change of antimalarial drug treatment policy. Malar $J$ 2013, 12:377.

39. Khalil IF, Alifrangis M, Tarimo DS, Staalso T, Satti GM, Theander TG, Ronn AM, Bygbjerg IC: The roles of the pfcrt $76 \mathrm{~T}$ and pfmdr1 $86 \mathrm{Y}$ mutations, immunity and the initial level of parasitaemia, in predicting the outcome of chloroquine treatment in two areas with different transmission intensities. Ann Trop Med Parasitol 2005, 99:441-448.

40. $\mathrm{MOH}$ : Anti-Malaria Drug Policy for Ghana. Accra, Ghana: Ministry of Health; 2009.

41. Kwansa-Bentum B, Ayi I, Suzuki T, Otchere J, Kumagai T, Anyan WK, Asahi H, Akao N, Wilson MD, Boakye DA, Ohta N: Administrative practices of health professionals and use of artesunate-amodiaquine by community members for treating uncomplicated malaria in southern Ghana: implications for artemisinin-based combination therapy deployment. Trop Med Int Health 2011, 16:1215-1224.

42. United Nation General Assembly: Implementation of General Assembly Resolution 66/289 on Consolidating Gains and Accelerating Efforts to Control and Eliminate Malaria in Developing Countries, Particularly in Africa, by 2015. 2012. United Nation document A/RES/66/289.

43. WHO: WHO Informal Consultation with Manufacturers of Artemisinin-Based Pharmaceutical Products in use for the Treatment of Malaria. Geneva: World Health Organization; 2007.

44. WHO: WHO briefing on Malaria Treatment Guidelines and artemisinin monotherapies. 2006. http://www.who.int/malaria/publications/atoz/ meeting_briefing19april.pdf.

45. Tucker M, Mutka T, Sparks K, Patel J, Kyle DE: Phenotype and genotype analysis of in vitro-selected artemisinin-resistance progeny of plasmodium falciparum. Antimicrob Agent Chemother 2012, 56:302-314.

46. Witkowski B, Amaratunga C, Khim N, Sreng S, Chim P, Kim S, Lim P, Mao S, Sopha C, Sam B, Anderson JM, Duong S, Chuor CM, Taylor WR, Suon S, Mercereau-Puijalon O, Fairhurst RM, Menard D: Novel pheno typic assays for the detection of artemisinin-resistant Plasmodium falciparum malaria in Cambodia in vitro and ex-vivo drug-response studies. Lancet Infect Dis 2013, 13:1043-1049.

47. $\mathrm{MOH}$ : Guidelines for Case Management of Malaria in Ghana. Accra: Ministry of Health; 2009.

48. WHO: Survey of the quality of selected antimalarial medicines circulating in six countries of sub-Saharan Africa. 2011. http://www.who.int/ medicines/publications/WHO_QAMSA_report.pdf.
49. Oduola AM, Milhous WK, Salako LA, Walker O, Desjardins RE: Reduced in-vitro susceptibility to mefloquine in West African isolates of Plasmodium falciparum. Lancet 1987, 2:1304-1305.

50. Simon F, Le BJ, Gaudebout C, Girard PM: Reduced sensitivity of Plasmodium falciparum to mefloquine in West Africa. Lancet 1988, 1:467-468.

51. Crockett $M$, Kain KC: Tafenoquine: a promising new antimalarial agent. Expert Opin Investig Drugs 2007, 16:705-715.

52. Pradines B, Mamfoumbi MM, Tall A, Sokhna C, Koeck UL, Fusai T, Mosnier J, Czarnecki E, Spiegel A, Trape JF, Kombila M, Rogier C: In vitro activity of tafenoquine against the asexual blood stages of Plasmodium falciparum isolates from Gabon, Senegal, and Djibouti. Antimicrob Agents Chemother 2006, 50:3225-3226.

53. Divo AA, Geary TG, Jensen JB: Oxygen- and time-dependent effects of antibiotics and selected mitochondrial inhibitors on Plasmodium falciparum in culture. Antimicrob Agents Chemother 1985, 27:21-27.

54. McColm AA, McHardy N: Evaluation of a range of antimicrobial agents against the parasitic protozoa, Plasmodium falciparum, Babesia rodhaini and Theileria parva in vitro. Ann Trop Med Parasitol 1984, 78:345-354.

55. Willerson D Jr, Rieckmann KH, Carson PE, Frischer H: Effects of minocycline against chloroquine-resistant falciparum malaria. Am J Trop Med Hyg 1972, 21:857-862

56. Dahl EL, Rosenthal PJ: Multiple antibiotics exert delayed effects against the Plasmodium falciparum apicoplast. Antimicrob Agents Chemother 2007, 51:3485-3490

57. WHO: Global Plan for Artemisinin Resistance Containment (GPARC). Geneva: World Health Organization; 2011.

doi:10.1186/1475-2875-12-450

Cite this article as: Quashie et al:: A SYBR Green 1-based in vitro test of susceptibility of Ghanaian Plasmodium falciparum clinical isolates to a panel of anti-malarial drugs. Malaria Journal 2013 12:450.

\section{Submit your next manuscript to BioMed Central and take full advantage of:}

- Convenient online submission

- Thorough peer review

- No space constraints or color figure charges

- Immediate publication on acceptance

- Inclusion in PubMed, CAS, Scopus and Google Scholar

- Research which is freely available for redistribution 